\title{
Pengaruh Servicescape Terhadap Kualitas Pelayanan
}

\author{
Oleh : \\ Erick Ferdinal $^{1 *}$ dan Sri Surjani Tjahjawati ${ }^{2}$ \\ ${ }^{1}$ Jurusan Administrasi Niaga, Politeknik Negeri Bandung, Indonesia \\ 2 Jurusan Administrasi Niaga, Politeknik Negeri Bandung, Indonesia
}

\begin{abstract}
:
Each company must strive to provide the best service to its customers to win the competition, thus the quality of service becomes one important. To provide good quality services to customers, the physical environment interaction between the company and the customer called with servicescape becomes consideration. Servicescape dimensions that are measured in this study are aesthetic facilities, lighting, ambience, layout, equipment, and employees, while for the service quality dimensions that are used in this study are tangible, reliability, responsiveness, assurance and empathy. The purpose of this study is to reveal the influence servicescape on service quality of Dana Pensiun Telkom Bandung City. 125 questionnaires distributed, but the data can be taken as many as 116. The data analysis is done is descriptive analysis, regression, and hypothesis testing. Based on the research that has been done, there is a positive influence of servicescape on quality service of Dana Pensiun Telkom Bandung.
\end{abstract}

Keywords: service, servicescape, service quality

\begin{abstract}
Abstrak:
Setiap perusahaan harus menyediakan pelayanan terbaik untuk para konsumen untuk dapat memenangkan persaingan. Oleh karena itu, kualitas pelayanan menjadi hal yang penting. Untuk dapat melayani komsumen dengan kualitas terbaik, interaksi lingkungan fisik antara perusahaan dan konsumen, yang disebut servicescape menjadi sebuah pertimbangan. Dimensi servicescape yang diukur dalam penelitian ini antara lain aestetik fasilitas, pencahayaan, suasana, layout, peralatan dan karyawan. Sedangkan dimensi kualitas pelayanan yang digunakan dalam penelitian ini adalah tangible, reliabilitas, responsifnes, jaminan dan empati. Studi ini bertujuan untuk melihat pengaruh servicescape pada kualitas pelayanan di Dana Pensiun Telkom Kota Bandung. 125 kuesioner disebarkan, tetapi data yang terkumpul hanya 116. Data analisis menggunakan analisis deskripsi, regresi dan uji hipotesis. Hasil penelitian menunjukkan bahwa terdapat hubungan yang positif dari servicescape pada kualitas pelayanan di Dana Pensiun Telkom Kota Bandung.
\end{abstract}

Kata kunci: pelayanan, servicescape, kualitas pelayanan

\section{PENDAHULUAN}

\section{Latar Belakang Penelitian}

Pertumbuhan ekonomi dunia berkembang pesat dimana persaingan

*Email korespondensi:

Erick Ferdinal

erick.ferdinal@yahoo.co.id dihadapi oleh setiap perusahaan, perusahaan berusaha memenangkan persaingan dengan strateginya masingmasing. Perusahaan berupaya memproduksi barang atau jasa yang dibutuhkan oleh pelanggan, perusahaan terus-menerus melakukan inovasi dan pembaharuan dalam meningkatkan 
kualitas setiap produknya baik berupa barang atau jasa, hal tersebut dilakukan agar dapat memenangkan persaingan, untuk dapat memenangkan persaingan dalam bisnis tentunya bukan hanya kualiatas produk atau jasa saja yang harus diperhatikan oleh perusahaan namun perusahaan juga harus memperhatikan kualitas pelayanan.

Kualitas pelayanan akan berdampak positif ataupun negatif yang mungkin akan mempengaruhi pada kepuasan pelanggan. Jika pelanggan puas atas pelayanan yang diberikan oleh perusahaan maka memungkinkan pelanggan tersebut akan loyal terhadap perusahaan namun apabila pelanggan kecewa atas pelayanan yang diberikan oleh perusahaan maka akan memungkinkan pelanggan terebut akan beralih untuk menggunakan produk atau jasa dari perusahaan yang lain, dengan demikian perusahaan harus memperhatikan kualitas pelayanan untuk mencapai kepuasan pelanggan, salah satu faktor untuk mencapai kepuasan pelanggan adalah kualitas dari pelayanan yang diberikan oleh perusahaan kepada pelangannya, semakin tingginya kualiatas pelayanan yang diberikan perusahaan kepada pelanggan maka kepuasan yang dirasakan pelanggan juga semakin tinggi. Kualitas pelayanan yang baik harus didikung juga dengan lingkungan fisik yang baik. Dalam persaingan bisnis yang semakin meningkat dan ketat perusahaan harus memperhatikan lingkungan fisik yang berinteraksi langsung dengan pelanggan atau yang disebut dengan servicescape.

Dana Pensiun Telkom merupakan anak perusahaan dari PT.Telkom yang menyelenggarakan Program Pensiun, hasil wawancara awal yang dilakukan penulis kepada 2 karyawan Dana Pesiun Telkom menyebutkan bahwa dalam penyampaian manfaat pensiun kepada pensiunan masih terjadi keterlambatan, dimana manfaat pensiun normalnya diterima oleh pensiunan mulai dari tanggal 1 sampai tanggal 20 disetiap bulannya, namun kenyataannya masih ada pensiunan yang terlambat menerima manfaat pensiun, hal ini tentunya menarik perhatian bagi penulis mengingat bahwa salah satu misi dari Dana Pensiun Telkom adalah Memelihara kesinambungan pembayaran manfaat pensiun secara tepat waktu, jumlah dan penerima. Hasil wawancara awal juga menyebutkan bahwa dalam melayani pensiunan terbagi menjadi dua yaitu pelayanan melalui telepon dan pelayanan langsung dimana para pensiunan datang langsung ke Dana Pensiun Telkom, dalam proses pelayanan baik melalui telepon ataupun pelayanan langsung adanya hambatan dalam menyampaikan informasi kepada para pensiunan yang sudah lanjut usia khususnya para lansia yang memiliki pendengaran yang kurang baik dan daya tangkap yang lemah, sehingga pernah terjadi salah paham yang mengakibatkan marahnya pensiunan atas pelayanan yang diberikan oleh karyawan Dana Pensiun Telkom. Pemberian manfaat pensiun kepada pensiunan PT.Telkom Indonesia dan pelayanan Dana Pensiun Telkom kepada pensiunan PT.Telkom Indonesia tentunya tidak terlepas dari peran servicescape didalamnya

Dana Pensiun Telkom tentunya harus memiliki servicescape yang mendukung kualitas pelayanan dalam kegiatan perusahaan untuk melayani para pensiunan PT.Telkom Indonesia, tentunya servicescape yang ada di Dana Pensiun Telkom harus disesuaikan dengan kondisi pensiunan PT. Telkom Indonesia yang pada umumnya berusia diatas usia 56 tahun ke atas, maka dari itu lingkungan fisik atau servicescape yang ada di Dana Pensiun Telkom harus sesuai dengan kondisi fisik dari pensiunan PT. Telkom Indonesia sehingga setiap pensiunan akan nyaman dan puas dengan servicescape dari Dana Pensiun Telkom. Bagi Dana Pensiun Telkom servicescape merupakan satu wujud dari jasa itu sendiri, sehingga 
diperkirakan bahwa servicescape dapat mempengaruhi kualitas pelayanan yang diberikan oleh pihak Dana Pensiun Telkom Kota Bandung kepada pensiunan PT. Telkom Indonesia. Berdasarkan uraian di atas, peneliti ingin melihat pengaruh servicescape terhadap kualitas pelayanan Dana Pensiun Telkom Kota Bandung. Maka dari itu penulis tertarik untuk melakukan penelitian dengan judul "Pengaruh Servicescape terhadap kualitas pelayanan Dana Pensiun Telkom Kota Bandung”.

\section{Identifikasi Masalah}

Berdasarkan uraian latar belakang diatas, maka identifikasi masalah dalam penelitian ini adalah sebagai berikut :

1. Bagaimana tingkat penerapan servicescape di Dana Pensiun Telkom Kota Bandung?

2. Bagaimana tingkat kualitas pelayanan Dana Pensiun Telkom Kota Bandung?

3. Apakah servicescape berpengaruh terhadap kualitas pelayanan Dana Pensiun Telkom kota Bandung?

\section{Tujuan Penelitian}

Penelitian ini memiliki beberapa tujuan diantaranya adalah sebagai berikut:

1. Untuk mengetahui tingkat penerapan servicescape di Dana Pensiun Telkom Kota Bandung

2. Untuk mengetahui tingkat kualitas pelayanan Dana Pensiun Kota Bandung.

3. Untuk mengetahui pengaruh servicescape terhadap kualitas pelayanan Dana Pensiun Telkom Kota Bandung.

\section{Hipotesis Penelitian}

Berdasarkan pembahasan dalam tinjauan pustaka, maka formulasi hipotesis yang diajukan untuk diuji kebenarannya dalam penelitian ini dirumuskan sebagai berikut:
$\mathrm{H}_{0}$ : Tidak terdapat pengaruh yang signifikan antara servicescape terhadap kualitas pelayanan.

$\mathrm{H}_{\mathrm{a}}$ : Terdapat pengaruh yang signifikan antara servicescape terhadap kualitas pelayanan

\section{TINJAUAN PUSTAKA \\ Servicescape}

Lingkungan fisik atau servicescape merupakan hal yang penting karena servicescape berinteraksi langsung dengan pelanggan dimana kesan yang pelanggan terima tentang jasa yang ditawarkan tergantung terhadap bukti-bukti fisik atau servicescape yang ditawarkan penyedia jasa, servicescape atau lingkungan fisik merupakan suatu hal yang secara nyata turut mempengaruhi keputusan konsumen untuk membeli dan menggunakan produk jasa yang ditawarkan (Hurriyati 2010;64). menurut Fitzsimmons dan Mona (2011:154) pengertian dari servicescape adalah fasilitas fisik yang mendukung fasilitas pelayanan yang mempengaruhi baik perilaku pelanggan ataupun perilaku karyawan dan harus dirancang dengan rasa dan suasana sehingga sebangun dengan konsep layanan, Sedangkan McDonnell dan Hall (2008) mengatakan bahwa servicescape adalah lingkungan fisik dimana didalamnya terjadi pertemuan jasa dan mempengaruhi persepsi pelanggan terhadap servicescape (persepsi kualitas) dan selanjutnya pada respon internal (tingkat kepuasan pelanggan) dan respon eksternal (perilaku untuk berlangganan dan membeli kembali). Sedangkan Hightower (2003) dalam Musriha berpendapat bahwa servicescape adalah lingkungan fisik perusahaan yang didesain untuk kebutuhan karyawan dan pelanggan akan lebih memuaskan bagi para pelanggannya daripada perusahaan yang tidak mempertimbangkan kebutuhan karyawan dan pelanggannya. Berdasarkan pengertian servicescape menurut para ahli diatas, dapat disimpulkan bahwa servicescape adalah lingkungan fisik perusahaan yang 
berinteraksi langsung dengan pelanggan sehingga pelanggan mendapatkan kesan atas interaksi yang terjadi.

Menurut Ryu dan Jang (2007) dimensi servicescape terdiri dari 6 dimensi yaitu sebagai berikut :

1. Estetika Fasilitas, mengacu pada desain arsitektur bersamaan dengan desain interior dan dekorasi, yang semuanya berkontribusi terhadap daya tarik lingkungan fisik. Aspek lain dari desain interior, misalnya seperti furniture, gambar lukisan, tanaman atau bunga, dekorasi dinding dapat juga meningkatkan persepsi kualitas lingkungan jasa, menciptakan respon internal dari pelanggan.

2. Pencahayaan menjadi salah satu rangsangan fisik yang dapat mempengaruhi pelanggan

3. Ambience, mengacu pada karakteristik latar belakang tidak berwujud yang cendrung mempengaruhi indra non visual dan dan memiliki efek bawah sadar pada pelanggan. Kondisi ini biasanya meliputi latar belakang, musik, aroma dan suhu udara.

4. Tata letak, berarti cara dimana objek (misalnya, mesin peralatan dan perabot) diatur dalam lingkungan. Tata letak memfasilitasi pemenuhan kebutuhan fungsional dan tata letak yang dirancang dengan baik agar dapat memfasilitasi pemenuhan kebutuhan hedonis atau kenikmatan dari pelanggan.

5. Peralatan, peralatan sebagai kualitas nyata yang paling penting dari jasa yang dapat mempengaruhi persepsi kualitas pelanggan.

6. Karyawan, yang sangat terkait dengan lingkungan sosial, merujuk pada pelayanan yang melayani pada lingkungan jasa. Karyawan disini berarti penampilan karyawan (penampilan profesional dan daya tarik) dan jumlah karyawan.

\section{Kualitas Pelayanan}

Beberapa ahli mengungkapkan pendapatnya mengenai pengertian dari kualitas pelayanan, berikut merupakan pengertian kualitas pelayanan menurut bebrapa ahli, Menurut Lewis dan Booms dalam Yousapronpaiboon (2011) kualitas pelayanan merupakan sebagai ukuran seberapa baik tingkat layanan yang diberikan mampu sesuai dengan harapan pelanggan, Sedangkan Menurut Tjiptono (2011) kualitas pelayanan adalah tingkat keunggulan yang diharapkan dan pengendalian atas tingkat keunggulan tersebut untuk memenuhi keinginan pelanggan, sedangkan menurut Zeithaml dan Bitner dalam Prabha dan Soolakshna (2010) kualitas pelayanan merupakan penyerahan atau penyampaian pelayanan secara relatif lebih unggul atau superior terhadap harapan pelanggan berdasarkan pendapat para ahli mengenai kualitas pelayanan, dapat disimpulkan bahwa kualitas pelayanan adalah tingkat layanan yang ditujukan agar dapat memenuhi harapan pelanggan menurut Parasuraman et al (1985) dalam Shahin dan Samea (2010), menyebutkan ada 5 dimensi kualitas pelayanan yaitu :

1. Tangibles (Bukti Fisik)

Fasilitas fisik, peralatan dan penampilan personil

2. Reliability (Kepercayaan)

Kemampuan untuk melakukan layanan yang dijanjikan dapt dipercaya dan akurat.

3. Responsiveness (Daya Tanggap)

Kesediaan untuk membantu pelanggan dan memberikan layanan yang cepat.

4. Assurance (Jaminan)

mencakup kompetensi, kesopanan, kredibilitas dan keamanan. Pengetahuan dan kesopanan karyawan dan kemampuan mereka untuk menginspirasi kepercayaan dan keyakinan.

5. Empathy (Empati)

Mencakup akses, komunikasi, memahami pelanggan, perusahaan 
memberikan

pelanggannya.

\section{Kerangka Pemikiran}

Dimensi dari servicescape adalah ambience, tata letak, pecahayaan, peralatan, karyawan dan estetika fasilitas. Lingkungan fisik atau servicescape merupakan hal yang penting karena servicescape berinteraksi langsung dengan pelanggan dimana kesan yang pelanggan terima tentang jasa yang ditawarkan tergantung terhadap bukti-bukti fisik atau servicescape yang ditawarkan penyedia jasa, servicescape atau lingkungan fisik merupakan suatu hal yang secara nyata turut mempengaruhi keputusan konsumen untuk membeli dan menggunakan produk jasa yang ditawarkan (Hurriyati 2010;64). Servicescape yang baik tentunya memiliki peran yang sangat penting dimana servicescape berperan memberikan gambaran visual untuk organisasi, dimensi lingkungan servicescape membuat organisasi dapat menyampaikan sasaran segmen pasarnya, Servicescape berperan memfasilitasi penyampaian layanan dengan baik, dapat membantu atau menghambat karyawan dalam mengerjakan pekerjaannya, Servicescape berperan mendorong interaksi sosial antara pelanggan. Misalnya, tata letak ruang tunggu yang memiliki beberapa kursi yang menyatu dengan meja sehingga mendorong interaksi sosial dan Servicescape berperan menjadi metode untuk perliaku karyawan, misalnya ruangan kerja karyawan disediakan kursi yang nyaman, lukisan dan musik inspiratif sehingga mendorong suasana hati yang baik untuk bekerja.

Pembagian

servicescape

dibedakan menjadi dua yaitu yaitu dibedakan berdasarkan pemakaian servicescape dan kompleksitas fisik servicescape, pemakaian servicescape mengacu pada siapa yang melakukan tindakan dalam servicescape yaitu pelanggan, karyawan atau keduanya.

Jurnal Riset Bisnis dan Investasi

Vol. 3, No. 1, April 2017

ISSN 2460-8211
Berdasarkan kompleksitas servicescape lingkungan jasa bisa dikelompokkan menjadi dua kategori yaitu lean environment, lingkungan jasa yang paling sederhana dengan sedikit elemen, sedikit ruang dan hanya segelintir peralatan dan elaborate environment, lingkungan jasa yang sangat kompleks, dengan banyak elemen dan banyak bentuk.

Dimensi dari kualitas pelayanan adalah dimensi tangibles (bukti fisik) yaitu fasilitas fisik, peralatan dan penampilan personil, dimensi selanjutnya adalah dimensi reliability (kepercayaan) yaitu mencakup kemampuan untuk melakukan layanan yang dijanjikan dapt dipercaya dan akurat, dimensi selanjutnya adalah diensi responsiveness (daya tanggap) yang mencakup kesediaan untuk membantu pelanggan dan memberikan layanan yang cepat, dimensi selanjutnya adalah dimensi assurance (jaminan) mencakup kompetensi, kesopanan, kredibilitas dan keamanan. Pengetahuan dan kesopanan karyawan dan kemampuan mereka untuk menginspirasi kepercayaan dan keyakinan. Dan dimensi kualitas pelayanan yang terakhir adalah dimensi empathy (empati) yaitu mencakup akses, komunikasi, memahami pelanggan, perusahaan memberikan perhatian kepada pelanggannya.

\section{Gambar 1 Kerangka Pemikiran}

\begin{tabular}{|c|c|}
\hline $\begin{array}{l}\text { Servicescape } \\
\text { (X) }\end{array}$ & $\begin{array}{c}\text { Kualitas Pelayanan } \\
\text { (Y) }\end{array}$ \\
\hline $\bar{v}$ & $\bar{v}$ \\
\hline Dimensi: & Dimensi: \\
\hline 1. Estetika & 1. Tangibles \\
\hline Fasilitas & 2. Reliability \\
\hline 2. Pencahayaan & 3. Responsivenes \\
\hline 3. Ambience & 4. Assurance \\
\hline 4. Tata Letak & 5. Empathy \\
\hline 5. Peralatan & \\
\hline
\end{tabular}

Sumber: Olah Data, 2016 
Berdasarkan pemikiran dan teori yang telah diuraikan, maka dalam penelitian ini penulis menempatkan servicescape sebagai variabel yang mempengaruhu (variabel $\mathrm{x}$ ) dan kualitas pelayanan pelayanan sebagai variabel yang dipengaruhi (variabel y). Sebagaimana yang telah dijelaskan sebelumnya servicescape mempunyai enam dimensi yaitu ambience, tata letak, pecahayaan, peralatan, karyawan dan estetika fasilitas, sedangkan kualitas pelayanan memiliki lima dimensi yaitu tangibles, reliability, responsiveness, assurance dan emphaty. Adapun kerangka pemikiran yang dikembangkan dalam penelitian ini adalah digambarkan pada gambar 1 .

\section{METODE PENELITIAN}

Metode yang digunakan dalam penelitian ini adalah metode penelitian kuantitatif, populasi pada penelitian yang digunakan yaitu seluruh pensiunan PT. Telkom Indonesia yang memiliki kepentingan mengenai kepensiunan dan datang ke Dana Pensiun Telkom Kota Bandung dari tanggal 18 Juni 2016 - 12 Juli 2016 yang berjumlah 125 orang sedangkan, penelitian ini menggunakan sampling Jenuh Jadi sampel pada penelitian ini berjumlah 125 responden. Berdasarkan kuesioner yang disebar kepada 125 responden hanya 116 kuesioner yang memenuhi syarat dimana 9 kuesioner lainnya tidak memenuhi syarat karena ada beberapa pertanyaan dari kuesioner yang tidak dijawab oleh responden. Data penelitian terdiri dari primer yaitu yang berasal dari kuesioner dan hasil wawancara, dan sekunder yang berasal dari studi pustaka dan data perusahaan.

Dalam penelitian ini, kuesioner yang digunakan didesain dengan menggunakan skala likert dengan bobot nilai 1 sampai dengan 5. Pada penelitian ini melakukan uji validitas dengan $\mathrm{N}=116$ signifikansi $5 \%$ maka ditemukan nilai rtabel yaitu 0,152 (Chaniago 2010) dan hasil dari uji validitas menyatakan pertanyaan yang digunakan dalam kesioner telah valid baik untuk variabel servicescape ataupun variabel kualitas pelayanan. Selain itu kedua variabel adalah reliabel, karena keduanya memiliki nilai cronbach's alpha yang lebih dari 0,60 (Sekaran, 2006:182) yaitu nilai variabel servicescape sebesar 0,945 dan nilai variabel kualitas pelayanan sebesar 0,919. Analisis dilakukan dengan menggunakan uji asumsi klasik, analisis deskriptif, analisis regresi, dan uji hipotesis.

\section{HASIL DAN PEMBAHASAN Identitas Responden}

Tabel 1 dan Tabel 2 adalah profil responden dalam penelitian ini.

Tabel 1 Klasifikasi Responden
Berdasarkan Jenis Kelamin
\begin{tabular}{|l|l|l|}
\hline Jenis Kelamin & Frekuensi & Persentase \\
\hline Laki-Laki & 69 & $59,5 \%$ \\
\hline Perempuan & 47 & $40,5 \%$ \\
\hline Total & 116 & $100 \%$ \\
\hline
\end{tabular}

Sumber : Data Olahan, 2016

Tabel 2 Klasifikasi Responden Berdasarkan Usia

\begin{tabular}{|l|l|l|}
\hline Usia & Frekuensi & Persentase \\
\hline 56-60 Tahun & 87 & $75 \%$ \\
\hline 61-65 Tahun & 27 & $23,3 \%$ \\
\hline.$>65$ tahun & 2 & $1,7 \%$. \\
\hline Total & 116 & $100 \%$ \\
\hline
\end{tabular}

Sumber: Data Olahan, 2016

\section{Analisis Deskriptif Variabel Servicescape}

Variabel servicescape memiliki jawaban responden terendah yaitu 2 dan jawaban responden tertingginya yaitu 5 . Berdasarkan tabel diatas nilai mean variabel servicescape menunjukan angka sebesar 4.0983, merujuk pada tabel 3.8 dimana mean dengan interval 3,41-4,20 berada pada tingkat yang tinggi. Standar deviasi variabel servicescape menunjukan angka 0,50600 atau sama dengan 12,34\% dari nilai mean artinya standar deviasi variabel servicescape tidak lebih dari $20 \%$ 
nilai meannya dan menunjukan bahwa variasi jawaban kecil atau sebagian besar responden menjawab dalam variabel ini dengan jawaban relatif sama.

Dari enam dimensi variabel sevicescape, dimensi karyawan yang merupakan dimensi dengan nilai mean terendah yaitu sebesar 3,9526 sedangkan dimensi estetika fasilitas merupakan dengan nilai mean tertinggi yaitu sebesar 4,2543 .

Tabel 3 Analisis Deskriptif Variabel Servicescape

\begin{tabular}{|l|l|l|l|l|}
\hline & Min & Max & Mean & $\begin{array}{l}\text { Std. } \\
\text { Dev. }\end{array}$ \\
\hline $\begin{array}{l}\text { Estetika } \\
\text { Fasilitas }\end{array}$ & 2,75 & 5,00 & 4,25 & 0,50 \\
\hline Pencahayaan & 2,67 & 5,00 & 4,06 & 0,65 \\
\hline Ambience & 2,67 & 5,00 & 4,04 & 0,62 \\
\hline Tata Letak & 2,50 & 5,00 & 4,16 & 0,59 \\
\hline Peralatan & 2,50 & 5,00 & 4,10 & 0,59 \\
\hline Karyawan & 2,25 & 5,00 & 3,95 & 0,63 \\
\hline Servicescape & 2,93 & 5,00 & 4,09 & 0,50 \\
\hline
\end{tabular}

Sumber: Data Olahan, 2016

Tabel 4 Analisis Deskriptif Dimensi Estetika Fasilitas

\begin{tabular}{|l|l|l|l|l|}
\hline & Min & Max & Mean & $\begin{array}{l}\text { Std. } \\
\text { Dev. }\end{array}$ \\
\hline $\begin{array}{l}\text { Papan Nama } \\
\text { Perusahaan } \\
\text { Terlihat Jelas }\end{array}$ & 2,00 & 5,00 & 4,36 & 0,58 \\
\hline $\begin{array}{l}\text { Logo Perusahaan } \\
\text { Terlihat Jelas }\end{array}$ & 3,00 & 5,00 & 4,31 & 0,62 \\
\hline $\begin{array}{l}\text { Papan Petunjuk } \\
\text { Terlihat Jelas }\end{array}$ & 2,00 & 5,00 & 4,23 & 0,68 \\
\hline $\begin{array}{l}\text { Dekorasi } \\
\text { Ruangan } \\
\text { Nyaman }\end{array}$ & 1,00 & 5,00 & 4,11 & 0,74 \\
\hline Estetika Fasilitas & 2,75 & 5,00 & 4,25 & 0,50 \\
\hline
\end{tabular}

Sumber: Data Olahan, 2016

\section{Analisis Deskriptif Variabel Kualitas Pelayanan}

Variabel kualitas pelayanan memiliki jawaban responden terendah yaitu 1 dan jawaban responden tertingginya yaitu 5. Berdasarkan tabel diatas nilai mean variabel kualitas pelayanan menunjukan angka sebesar
4,0891 merujuk pada tabel 3.8 dimana mean dengan interval 3,41 - 4,20 berada pada tingkat yang tinggi. Standar deviasi variabel kualitas pelayanan menunjukan angka 0,49505 atau sama dengan 12,10\% dari nilai mean artinya standar deviasi variabel kualitas pelayanan tidak lebih dari $20 \%$ nilai meannya dan menunjukan bahwa variasi jawaban kecil atau sebagian besar responden menjawab dalam variabel ini dengan jawaban relatif sama.

Dari lima dimensi variabel kualitas pelayanan, dimensi assurance yang merupakan dimensi dengan nilai mean terendah yaitu sebesar 3,8707 sedangkan dimensi reliabillity merupakan dengan nilai mean tertinggi yaitu sebesar 4,2931.

\section{Analisis Regresi}

Berdasarkan tabel 5, dapat dilihat bahwa konstanta sebesar 14,300 (a) dengan koefisien regresi linier sebsar 0,799 (b). Dari hasil tersebut diperoleh hasil model regresi sederhana sebagai berikut .

$\mathrm{Y}=\mathrm{a}+\mathrm{bX}$

$Y=14,300+0,799 X$

Nilai a dan $b$ dapat diinterpretasikan sebagai berikut:

1. Konstanta sebesar 14,300 dapat diartikan jika servicescape sama dengan nol $(\mathrm{X}=0)$ atau tidak ada servicescape, maka kualitas pelayanan hanya sebesar 0,799

2. Servicescape memiliki nilai koefisien regresi linier sederhana sebesar 0,799. Hal ini mengandung arti bahwa apabila servicescape mengalami kenaikan satu satuan maka kualitas pelayanan akan mengalami kenaikan 0,799 satuan.

Tabel 5 Uji Regresi Linier Sederhana

\begin{tabular}{|l|l|l|l|l|l|}
\hline \multirow{2}{*}{ Model } & \multicolumn{2}{|l|}{ Unstand. Coe. } & Std. Coe. & t & Sig. \\
\cline { 2 - 6 } & B & Std. Er & Beta & & \\
\hline (Constant) & 14,30 & 3,92 & & 3,64 & 0,0 \\
\hline Servicescape & 0,61 & 0,04 & 0,79 & 14,17 & 0,0 \\
\hline
\end{tabular}

Sumber: Data Olahan, 2016 
Tabel 6 Uji F

\begin{tabular}{|ll|l|l|l|l|l|}
\hline \multicolumn{2}{|l|}{ Model } & Sum of Squares & df & Mean Square & F & Sig. \\
\hline \multirow{4}{*}{1} & Regression & 5234,725 & 1 & 5234,725 & 200,780 &, $000^{\mathrm{b}}$ \\
& Residual & 2972,197 & 114 & 26,072 & & \\
& Total & 8206,922 & 115 & & & \\
\hline
\end{tabular}

Sumber: Data Olahan, 2016

Tabel 7 Koefisien Determinasi

\begin{tabular}{|l|l|l|l|l|}
\hline Model & R & R Square & Adjusted R Square & Std. Error of the Estimate \\
\hline 1 &, $799^{\mathrm{a}}$ &, 638 &, 635 & 5,10607 \\
\hline
\end{tabular}

Sumber: Data Olahan, 2016

\section{Uji Hipotesis}

Untuk mengetahui servicescape berpengaruh signifikan terhadap kualitas pelayanan, maka dilakukan uji hipotesis. Pengujian hipotesis menggunakan uji $\mathrm{F}$ test (Anova) dengan tingkat signifikansi $\mathrm{a}=5 \%$ atau 0,05 dan nilai $\mathrm{F}$ tabel adalah 3,92 dengan rumusan hipotesis dengan rumusan sebagai berikut :

$\mathrm{H} 0$ = Tidak terdapat pengaruh yang signifikan antara servicescape terhadap kualitas pelayanan.

$\mathrm{Ha}=$ Terdapat pengaruh yang signifikan antara servicescape terhadap kualitas pelayanan.

Dalam penelitian ini, uji hipotesis yang digunakan adalah uji statistik $F$. Berdasarkan tabel 6 diketahui bahwa $\mathrm{F}$ hitung adalah 200,780 sedangkan nilai $\mathrm{F}$ tabel adalah 3,92. Nilai $F$ hitung $\geq F$ tabel dapat disimpulkan bahwa $\mathrm{H}_{0}$ ditolak, maka hasil dari uji hipotesis ini adalah terdapat pengaruh yang positif dan signifikan antara servicescape dengan kualitas pelayanan.

Untuk mengetahui seberapa besar pengaruh dari servicescape terhadap kualitas pelayanan maka dapat dilihat dari hasil tabel 6 dan tabel 7. Dari tabel 7 diketahui bahwa nilai $\mathrm{R}$ adalah 0,799 yang berarti nilai hubungan servicescape dengan kualitas pelayanan adalah sebesar 0,799 . Nilai $R$ square sebesar 0,638 atau $63,8 \%$ memiliki arti bahwa besar pengaruh variable servicescape terhadap variabel kualitas pelayanan adalah sebesar $63,8 \%$ sedangkan sisanya dipengaruhi oleh variabel lain.

\section{KESIMPULAN DAN SARAN Kesimpulan}

Berdasarkan penelitian yang dilakukan, maka dapat ditarik kesimpulan. Kesimpulan ini sekaligus menjawab identifikasi masalah penelitian yaitu :

1. Tingkat penerapan servicescape di Dana Pensiun Telkom Kota Bandung sudah baik, dari total 6 dimensi yang ada pada variabel servicescape ada 5 dimensi berada pada tingkat yang tinggi sedangkan 1 dimensi lainnya memiliki tingkat penerapan yang sangat tinggi.

2. Tingkat kualitas pelayanan Dana Pensiun Kota Bandung telah baik. Dari total 5 dimensi yang ada pada variabel kualitas pelayanan ada 4 dimensi yang memiliki tingkat yang tinggi sedangkan 1 dimensi lainnya memiliki tingkat penerapan yang sangat tinggi.

3. Terdapat pengaruh servicescape terhadap kuallitas pelayanan Dana Pensiun Telkom Kota Bandung. Servicescape memiliki pengaruh yang positiif dan signifikan terhadap kualitas pelayanan yaitu sebesar $63,8 \%$ dan sisanya sebesar $36,2 \%$ digambarkan atau dijelaskan oleh variabel atau faktor lain yang tidak diteliti. 
Saran

Berdasarkan hasil penelitian yang terlah dilakukan, penulis memberikan saran sebagai berikut :

1. Merujuk pada hasil penelitian bahwa servicescape Dana Pensiun Telkom Kota Bandung telah baik, namun untuk meningkatkan servicescape Dana Pensiun Telkom Kota Bandung, penulis memberikan saran bahwa Dana Pensiun Telkom Kota Bandung sebaiknya meningkatkan dimensi estetika fasilitas dimana Dana Pensiun Telkom Kota Bandung dapat menambahkan dekorasi baru pada ruang tunggu seperti gambar lukisan, tanaman atau bunga sehingga mencitptakan suasana baru yang lebih menyenangkan baik bagi karyawan Dana Pensiun Telkom Kota Bandung ataupun bagi pensiun PT. Telkom Indonesia.

2. Merujuk pada hasil penelitian, bahwa tingkat kualitas pelayanan Dana Pensiun Telkom Kota Bandung telah baik, namun untuk meningkatkan kualitas pelyanan Dana Pensiun Telkom Kota Bandung, penulis memberikan saran bahwa Dana Pensiun sebaiknya memperhatikan dan meningkatkan kebersihan ruang tunggu, selain itu Dana Pensiun Telkom Kota Bandung juga harus memperhatikan keakuratan informasi yang diberikan. Dimana informasi yang diberikan harus disesuaikan dengan kondisi pensiunan. Apabila pensiunan sangat sulit mengerti dengan informasi yang diberikan yang dikarenakan daya tanggap pensiunan yang sudah melemah ataupun pendengaran pensiunan yang sudah berkurang, sebaiknya pensiunan tersebut dihimbau untuk ditemani dengan anggota keluargnya sehingga informasi yang berikan dapat juga diberikan kepada anggota keluargnya dengan demikian pensiunan mendapatkan informasi yang diinginkannya.

DAFTAR PUSTAKA

Chaniago, J. (2010). Tabel $r$ Koefisien Korelasi Sederhana. Dipetik Juni 23, 2016, dari PPS UNUD: http://www.pps.unud.ac.id

Fitzsmmons, J. A., \& J. Fitzsmmons, M. (2011). Service Management: Operations, Strategy, Information Technology. New York: McGraw-Hill.

Hurriyati, R. (2010). Bauran Pemasaran dan Loyalitas Konsumen. Bandung: Alfabeta.

McDonnell, A., \& Michael, H. C. (2008). A Framework of Evaluation of Winery Servicescape: A New Zealand Case Vol. 6 No. 2. Dipetik Aprl 04, 2016, dari Pasosonline: http://www.pasosonline.org

Musriha. (2011). Pengaruh Servicescape dan Kualitas Komunikasi Karyawan Terhadap Loyalitas Nasabah Melalui Kepuasan Nasabah Bank Mandiri di Surabaya. Dipetik Februari 24, 2016, dari Jurnal STIESIA: http://jurnal.stiesia.ac.id

Prabha Ramseook, M., \& Soolakshna, D. L.-B. (2010). Service Quality in Public Service Vol. 3 No. 1. Dipetik Aprl 20, 2016, dari http://www.observgo.uquebec

Ryu, \& Jang, S. (2007). The Effect of Environmental Perception on Behavioral Intention Through Emotion: The Case of Upscale Restaurant. Journal of Hospital and Tourism Research, Vol. 31 No. 1.

Sekaran, U. (2006). Metode Penelitian untuk Bisnis. Jakarta: Jayakarsa.

Shahin, A., \& Samea, M. (2010). Developing the Models of Service Quality Gaps: A Critical Discussion Vol. 1 No. 1. Dipetik Aprl 11, 2016, dari http://macrothink.org

Sugiyono. (2005). Statistik Untuk Penelitian. Bandung: Alfabeta. 
Sugiyono. (2010). Metode Penelitian Bisnis. Bandung: Alfabeta.

Sugiyono. (2012). Metode Penelitian Kombinasi. Bandung: Alfabeta.

Sugiyono. (2013). Metode Penelitian Kuantitatif, Kualitatif dan $R \& D$. Bandung: Alfabeta.

Tjiptono, F. (2011). Pemasaran Jasa. Malang: Bayumedia.

Yousapronpaiboon, K. (2014). Measuring Higher Education Service Quality in Thailand. Dipetik Aprl 25, 2016, dari http://www.sciencedirect.com 